\section{B A Institute of \\ YK Business Administration \\ 六下 \\ Karachi \\ Leadership and Ideas for Tomorrow}

Business Review

Volume 15 Issue 1

January-June 2020

$1-1-2020$

\title{
Fiscal policy transmission mechanism in Pakistan: A general equilibrium analysis
}

\author{
Muhammad Raashid \\ Pir Mehr Ali Shah Arid Agriculture University, Rawalpindi, Pakistan \\ Abdul Saboor \\ Pir Mehr Ali Shah Arid Agriculture University, Rawalpindi, Pakistan \\ Shahzad Ahmad \\ State Bank of Pakistan and Institute of Business Administration, Karachi, Pakistan
}

Follow this and additional works at: https://ir.iba.edu.pk/businessreview

Part of the Finance Commons, Management Sciences and Quantitative Methods Commons, and the Marketing Commons

\section{(c) (1)}

This work is licensed under a Creative Commons Attribution 4.0 International License.

\section{Recommended Citation}

Raashid, M., Saboor, A., \& Ahmad, S. (2020). Fiscal policy transmission mechanism in Pakistan: A general equilibrium analysis. Business Review, 15(1), 50-66. Retrieved from https://doi.org/10.54784/

1990-6587.1009

This article is brought to you by iRepository for open access under the Creative Commons Attribution 4.0 License and is available at https://ir.iba.edu.pk/businessreview/vol15/iss1/10. For more information, please contact irepository@iba.edu.pk. 


\title{
Fiscal policy transmission mechanism in Pakistan: A general equilibrium analysis
}

\author{
Muhammad Raashid • Abdul Saboor • \\ Shahzad Ahmad
}

\begin{abstract}
This paper explores the impact of fiscal spending on key macroeconomic indicators for Pakistan economy using an estimated open economy new Keynesian dynamic stochastic general equilibrium (DSGE) model. Results show that a positive shock to government consumption leads to fall in private consumption, private investment and exports owing to negative wealth effect, rise in interest rate and domestic currency appreciation, respectively. Imports and inflation also rise. Estimated values of present value fiscal multipliers are 0.54, 0.29 and 0.18 after 1 year, 5 years and 10 years, respectively. These results show that although positive in the short run, yet the magnitude of the fiscal multiplier is very low in the case of Pakistan. Sensitivity analysis shows that the value of the multiplier marginally rises with rise in degree of price stickiness. Transitory shocks have a substantially higher multiplier relative to persistent shocks.
\end{abstract}

Keywords General equilibrium · Models and applications · Fiscal policy

\section{Introduction}

Objective of this study is to explore fiscal policy transmission mechanism in Pakistan. For this purpose, we focus upon expenditure side of fiscal policy and assess how variations in government expenditure affect key macroeconomic variables like GDP, inflation, employment, consumption, investment, imports, exports, interest rate and exchange rate $^{1}$. We use estimated open economy dynamic

Muhammad Raashid

Pir Mehr Ali Shah Arid Agriculture University, Rawalpindi-Pakistan

Email: mraashid505@gmail.com

Abdul Saboor

Pir Mehr Ali Shah Arid Agriculture University, Rawalpindi-Pakistan

Shahzad Ahmad

State Bank of Pakistan and Institute of Business Administration, Karachi-Pakistan

(C) Raashid, M., Saboor. A and Ahmad, S. 2020

1 We are not analyzing implications of variations in tax revenues for two reasons. First, tax revenues are not a fiscal policy variable due to their rigidity. Second, direct taxes are applicable only to a limited fraction of economy due to existence of a large informal sector. 
stochastic general equilibrium model (DSGE) presented in Ahmad and Haider (2019). Using this estimated DSGE model, we study fiscal policy transmission mechanism by analyzing impulse response functions (IRFs) of important macroeconomic variables to government consumption shock. Along with estimation of IRFs, we compute present value and cumulated versions of output multipliers at different horizons. In an easy to interpret and more familiar manner, these multipliers inform about change in GDP owing to one rupee change in government expenditure at different horizons e.g. one quarter, one year, two year etc. We also analyze how the magnitude of fiscal multipliers change when the level of price stickiness and persistence of fiscal expenditure change.

Our study of fiscal policy transmission through a DSGE model is motivated by following reasons:

First, Pakistan has been persistently facing problem of high budget deficit that has led to gradual buildup of high level of sovereign indebtedness ${ }^{2}$. This expansionary fiscal policy stance, as represented by persistently high deficits, complicates macroeconomic management in several ways. Important costs may include crowding out of private investment, rise in inflation and trade deficit. Evaluation of transmission mechanism and estimation of fiscal multipliers enables policy makers to evaluate costs and benefits of such an expansionary policy stance.

Second reason to study fiscal policy transmission mechanism in Pakistan is that the monetary policy transmission mechanism is weak. Ahmad et al (2016) show that interest rate shocks in a VAR model have negligible effects upon GDP. Similarly, monetary policy indicators have limited capability of explaining output fluctuations. Against this backdrop, fiscal policy becomes more important as a demand management tool and requires appropriate evaluation of transmission mechanism.

Finally, we observe that generally, Pakistan specific studies on fiscal transmission have two things in common: annual data and use of VAR models. Annual data is used as national income accounts are maintained only on an annual basis in Pakistan whereas VAR models are used to avoid the econometric issues related to simultaneity. A large number of estimated parameters and a small number of annual data observations reduce degrees of freedom to an extent that precludes rich specification of the VAR model. This issue has forced researchers towards estimation of too parsimonious models; potentially missing important dynamics. Khalid et al (2007) admit that their parsimonious model might have missed some important dynamics. Apart from degrees of freedom problem, other issues related to VAR models are the atheoretic nature and subjectivity to Lucas critique. Considering these limitations, Javid and Arif (2009) recommend that using a VAR model based upon DSGE model restrictions could present better analysis. Our study attempts to fill this gap by presenting a DSGE model based analysis of fiscal policy transmission mechanism.

Rest of the paper is organized as follows. Section 2 presents the literature review. Section 3 briefly describes model and calibration. Section 4 presents

\footnotetext{
2 During last 20 years (FY99-FY19), average budget deficit was 5 percent of GDP. At the end of fiscal year 2019, Pakistan's total debt and liabilities to GDP ratio was 88.9 percent.
} 
M. Raashid et al.

results that include impulse response functions, values of multipliers and sensitivity analysis for different parameterizations. The last one; section 5 concludes.

\section{Literature review}

Fiscal policy is one of the central tools of macroeconomic management. Notwithstanding the fact, considerable amount of disagreement exists regarding impact of fiscal spending on output and other important macro variables. In a comprehensive survey paper, Fontana (2009) informs that academic literature has no consensus even about sign of fiscal multipliers; let alone their magnitude. This disagreement stems from different theories, empirical methodologies and a range of country specific factors. At a broad level, there are two theories namely neoclassical and new Keynesian and, two empirical methodologies to explain fiscal transmission mechanism. Major country specific factors that affect fiscal transmission include trade openness, exchange rate regime, level of development, and sovereign indebtedness.

Neoclassical theory assumes flexible prices and wages. This theory predicts that rise in current fiscal spending leads to negative wealth effect in the households as they perceive rise in future taxes leading to decline in lifetime income. This decline in lifetime income leads to lower amount of consumption and leisure as both are considered normal goods. Decline in leisure demand implies rise in labor supply which leads to decline in real wage rate and rise in output. In sum, neoclassical theory predicts that rise in government consumption leads to decline in private consumption, rise in labor supply, decline in real wage and rise in output; indicating marginally positive multiplier. New Keynesian theory; on the other hand, believes in monopolistic competition and sticky prices in the goods market. This theory predicts that a rise in government demand makes firms raise their production level as they cannot translate rise in demand into a corresponding rise in price due to sticky prices. Heightened level of production culminates into higher labor demand and real wage which in turn increases household's consumption.

Apart from economic theories, disagreement in magnitude of fiscal multipliers is also attributable to the empirical methodologies used to estimate them. In order to ensure unbiased econometric analysis of fiscal policy transmission, empirical methodologies strive to identify exogenous or random component of government spending ${ }^{3}$. Fontana (2009) describes two main approaches to identify exogenous component of government spending: "narrative record" and structural vector autoregressions (SVAR). "Narrative record" or "dummy variable" approach was first used by Ramey and Shapiro (1998) in context of fiscal policy. With a view to identify shocks to government spending that were exogenous to the state of the domestic economy, they analyzed implications of large USA

\footnotetext{
3 Fontana (2009) describes two main components of fiscal spending: expenditures related to built-in stabilizers (aka cyclical budget component) and discretionary fiscal policy actions (aka structural budget component). Discretionary fiscal expenditures can be further divided into two components namely endogenous (systematic) component and exogenous (random) component. Empirical analysis strives to identify this exogenous or random part of discretionary fiscal expenditures to study transmission of fiscal policy.
} 
military buildups which were primarily motivated by foreign policy. They show that; similar to neoclassical predictions, rise in government spending leads to rise in output but decline in private consumption and real wage rate.

The SVAR based empirical approach to identify exogenous component of government spending was introduced by Blanchard and Perotti (2002). Their approach; primarily involving 3-variable SVAR including government spending, tax revenue and GDP, identifies the exogenous component based on restrictions on VAR coefficients inferred from institutional knowledge and timing of responses. Similar to new Keynesian theory, Blanchard and Perotti (2002) SVAR shows that fiscal spending leads to rise in output, consumption and real wage. Based on a survey of existing approaches, Ramey (2011) conclude that in the post Global Financial Crisis environment in USA, the value of temporary and deficit-financed government purchase stimulus could be in the range of 0.8-1.5.

Ilzetzki et al (2013), using a quarterly dataset of 44 developed and developing countries, show that value of government consumption multipliers depends upon a range of country-specific factors including level of economic development, exchange rate regime, trade openness and level of government debt. The authors show that value of fiscal multiplier is lower if a country is less developed and exchange rate is flexible. Further, government consumption multiplier is negative if trade is more open and public debt is high. However, in case of developing countries, unlike government consumption multiplier, government investment multipliers are positive.

After reviewing international literature, we focus upon Pakistan-specific studies of fiscal transmission. More recently, Munir and Riaz (2019) present how aggregate as well as different components of government expenditure and revenue affect macro variables in Pakistan. The study uses (mechanically interpolated) quarterly data from 1976Q1 to 2017Q4 in recursive VAR model estimated using log of variables. Results show that rise in aggregate and components of government expenditures leads to rise in GDP, private consumption, interest rate and prices while private investment falls. However for aggregate as well as for components, all reported IRFs are statistically insignificant for most part of the plot range (20 quarters). Further, although authors have not computed numeric value of multipliers but except for interest rate and private investment, magnitude of response functions is also quite low; less than 1 percent.

Using annual data from 1971-2008 in natural logs, Javid and Arif (2009) estimate a recursive VAR model. Ordering of recursive VAR is government spending, private consumption, GDP, interest rate, real exchange rate and debt-GDP ratio. In another specification, the authors use tax-GDP ratio instead of debtGDP ratio. In both specifications, the reported IRFs show that in response to government spending shock, GDP, private consumption and interest rate increase while response of real exchange does not appear to be robust w.r.t. to change in specifications. In first specification (debt-GDP) exchange rate appreciates for first four years and then depreciates while in tax-GDP specification, exchange rate depreciates for all ten years. The authors conclude that standard neoclassical model can account for effects of fiscal spending shock reasonably well in case of Pakistan. 
M. Raashid et al.

Khalid and ul Haq Satti (2016) estimate Blanchard and Perotti (2002) type SVAR model for aggregate as well as different components of government expenditures using annual data. Their results show that GDP rises in response to rise in aggregate government expenditures. They use three specifications of aggregate expenditures model that include SVAR with deterministic trend, stochastic trend and with error correction term. Positive sign of fiscal expenditures multiplier turn out to be robust w.r.t. these three specifications.

Khalid et al (2007) estimate fiscal reaction function and near-VAR model using three variables output gap, inflation and budget deficit-GDP ratio for annual data from 1965-2006. Their results show that output gap and inflation responses to budget deficit-GDP ratio shock are statistically insignificant. They conclude that fiscal policy is endogenous and pro-cyclical.

\section{Model}

We use Ahmad and Haider (2019) estimated DSGE model which is a modified version of Adolfson et al (2007). Three reasons justify the use of this model for studying fiscal policy transmission mechanism in the context of Pakistan. First, the general equilibrium model is based on new neoclassical synthesis (NNS) which combines features of both neoclassical as well as new Keynesian theories. As discussed in the literature review section, both schools of thought have differing views on fiscal transmission. This union of both schools of thought allows incorporation of elements from both sides; thereby allowing comprehensive analysis of the issue.

Second, as discussed in the literature review section, Ilzetzki et al (2013) show that value of fiscal multipliers varies with the level of trade openness and exchange rate regime. The model is particularly rich in terms of open economy modeling and therefore appropriately incorporates these elements while estimation of fiscal multipliers. Finally, the model has been estimated using Bayesian Maximum Likelihood estimation (BMLE) approach and evaluated through pseudo out-of-sample forecasting performance for GDP growth, inflation, interest rate and exchange rate for Pakistan by Ahmad and Haider (2019). Results of this forecast performance exercise show that the model has forecasting performance comparable with VAR and Bayesian VAR models in the medium term.

The mode ${ }^{4}$ mainly captures the behavior of five sectors: firms, households, fiscal authority, monetary authority and external sector. Firms are divided in three broad classes: domestic firms, importing firms and exporting firms. Importing firms are further classified as consumption goods importing firms and investment goods importing firms. All types of firms face Calvo (1983) type time dependent price revision constraints. Households derive utility from consumption, leisure and cash holding. Households' consumption and investment contain domestic as well as foreign components.

\footnotetext{
${ }^{4}$ For a detailed derivation of model equations, please see working paper version of Adolfson et al (2005). A working code to replicate their model can be extracted from Macroeconomic Model Database (MMB) initiated by Wieland et al (2012).
} 
Households' wages are subject to Calvo-type wage-revision constraints on the lines of Erceg et al (2000). Households' preferences are subject to habit persistence and they face real frictions like investment adjustment costs and variable capacity utilization. These modeling features are necessary to capture important dynamic effects of monetary policy actions on inflation, output, consumption and investment (Christiano et al (2005)).

Fiscal authority runs a balanced budget. Expenditure side includes government purchases of goods and services and transfer payments. Government purchases include government consumption as well as government investment; which is assumed to be non-productive. Revenues are gathered from different types of taxes such as labor income tax, capital income tax, payroll tax, consumption tax and, seigniorage. Fiscal spending has been modeled as a first order autoregressive process.

Central bank adjusts nominal interest according to Taylor type interest rate rule. Taylor rule incorporates interest rate smoothing, inflation and output gap fluctuations. Dynamic behavior of foreign variables has also been modeled through autoregressive processes for inflation, output and interest rate.

Final $\log$-linearized equations are presented in appendix 5.1 while values of parameters, that have been taken from calibrated as well estimated values of Ahmad and Haider (2019) are presented in appendix 5.6 .

\section{Results}

4.1 Impulse response functions

Impulse response functions obtained by solution of log-linearized model presented in appendix 5.1 are presented in figure 1. Log-linearized model represents variables as deviations from steady state value. To facilitate interpretation, IRFs are converted into "percent deviation from steady state" by multiplying with 100. One standard deviation shock in government spending, that turns out to be around 12 percent of steady state value of fiscal spending, leads to around 2 percent increase in GDP relative to steady state. The model assumes balanced budget. Rise in government spending and corresponding rise in taxes leads to negative wealth effect that lowers demand for consumption as well as leisure. Decline in leisure demand translates into increase in labor supply; causing decline in real wage. This decline in real wage leads to around -0.5 percent decline in private consumption.

Based on survey estimates reported in Choudhary et al (2016), our baseline calibration assumes that degree of price stickiness in domestic production sector, $\xi_{d}$ is equal to 0.25 . This implies lower degree of price stickiness indicating close to

\footnotetext{
5 Since we have not re-estimated the model, therefore; in case of estimated parameters, estimated posterior mean values of Ahmad and Haider (2019) are used as calibrated values of coefficients for this study.
} 

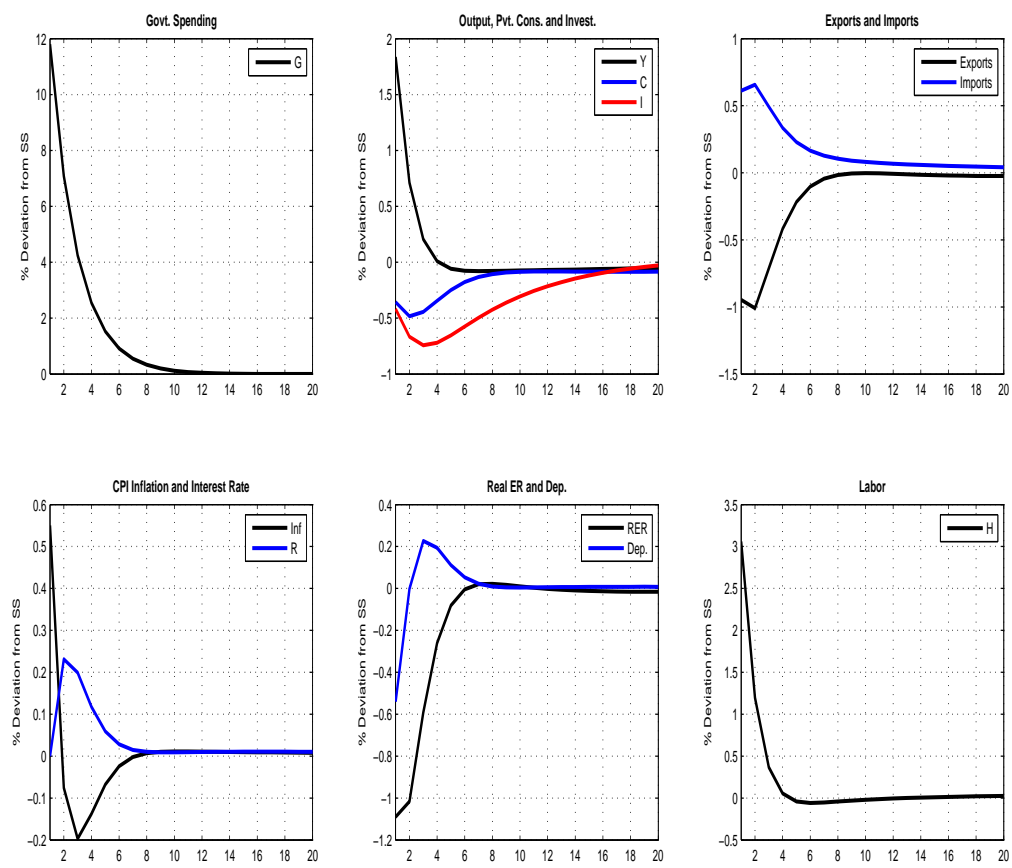

Fig. 1: Impulse response functions for baseline calibration

flexible prices. Since firms involved in business of importing consumption and investment goods operate in this almost-flexible price environment, therefore there price stickiness coefficients $\left(\xi_{m, c}\right.$ and $\left.\xi_{m, i}\right)$ are also assumed to be equal to 0.25 . Owing to low level of price stickiness, rise in government demand leads to rise in inflation. This rise in inflation prompts the central bank to raise interest via Taylor-type interest rate rule. Rise in interest rate leads to decline in private investment around -0.5 percent at impact; peaking at around 0.75 percent. Decline in investment appears to be more persistent than decline in private consumption.

Along with lowering private investment, rise in interest rate invites FX inflows which cause real exchange rate appreciation equivalent to 1 percent. Real appreciation boosts imports ( 0.5 percent) and discourages exports (- 1 percent).

\subsection{Fiscal multipliers}

Fiscal multiplier is defined as one rupee change in real GDP owing to one rupee change in government spending. Using information from IRFs of fiscal spending and GDP, we compute multipliers for 40 quarters. As informed earlier, IRFs show deviations from steady states. To convert these deviations into rupee terms, we multiply them with corresponding steady state values of fiscal 
spending and real GDP. Present value fiscal multipliers are calculated as:

$$
\Lambda_{T}^{P V}=\frac{\sum_{i=0}^{T}\left(\frac{1}{r}\right)^{i} \hat{y}_{t+i} \bar{y}}{\sum_{i=0}^{T}\left(\frac{1}{r}\right)^{i} \hat{g}_{t+i} \bar{g}}
$$

Cumulative multipliers have been calculated as:

$$
\Lambda_{T}^{\text {cum }}=\frac{\sum_{i=0}^{T} \hat{y}_{t+i} \bar{y}}{\sum_{i=0}^{T} \hat{g}_{t+i} \bar{g}}
$$

where $\hat{y}_{t+i}$ is IRF value for GDP, $\bar{y}$ is steady state value of GDP. Similar notations follow for fiscal spending. Discount factor to compute present value has been worked out by taking inverse of real interest rate $r$. Present value multipli-

Table 1: Present value fiscal multipliers

\begin{tabular}{c|c|cc|cc}
\hline & Baseline & \multicolumn{2}{c}{ Variations in Price Stickiness } & \multicolumn{2}{c}{ Variations in Persistence } \\
\hline Horizon & $\xi=0.25 ; \rho_{g}=0.6$ & $\xi=0.50$ & $\xi=0.75$ & $\rho_{g}=0$ & $\rho_{g}=0.9$ \\
\hline 1Q & 0.78 & 0.84 & 0.89 & 0.86 & 0.68 \\
4Q & 0.54 & 0.6 & 0.69 & 0.61 & 0.45 \\
8Q & 0.43 & 0.46 & 0.51 & 0.56 & 0.34 \\
16Q & 0.33 & 0.36 & 0.39 & 0.5 & 0.24 \\
20Q & 0.29 & 0.32 & 0.36 & 0.47 & 0.2 \\
40Q & 0.18 & 0.21 & 0.26 & 0.39 & 0.06 \\
\hline
\end{tabular}

ers are reported in table 1. For baseline calibration, impact multiplier is positive and 0.78 . However, the value of the multiplier gradually declines to 0.29 by 20 th quarter. To proxy long run multiplier, we calculate present value multiplier after 10 years i.e. 40 quarters which turns out to be 0.18 . To calculate present value multiplier, we use discount factor which is computed on the basis of average real interest rate using 6-months T-Bill rate and YoY CPI inflation. The average annual real interest rate computed over the sample period 2002Q2-2019Q4 is calculated to be 0.30 percent; which is quite low. Owing to low level of real interest rate and corresponding discount factor, present value and cumulative multipliers appear to be so close that we have not reported them.

\subsection{Sensitivity analysis}

We conduct sensitivity analysis to analyze the extent to which our computed multipliers are susceptible to changes in price stickiness parameter and persistence of government spending.

As informed earlier, we have assumed that index of price stickiness for domestic production, consumption importers and investment goods importers is assumed to be same. Baseline calibration assumes that $\xi_{d}=\xi_{m, c}=\xi_{m, i}=0.25$. 

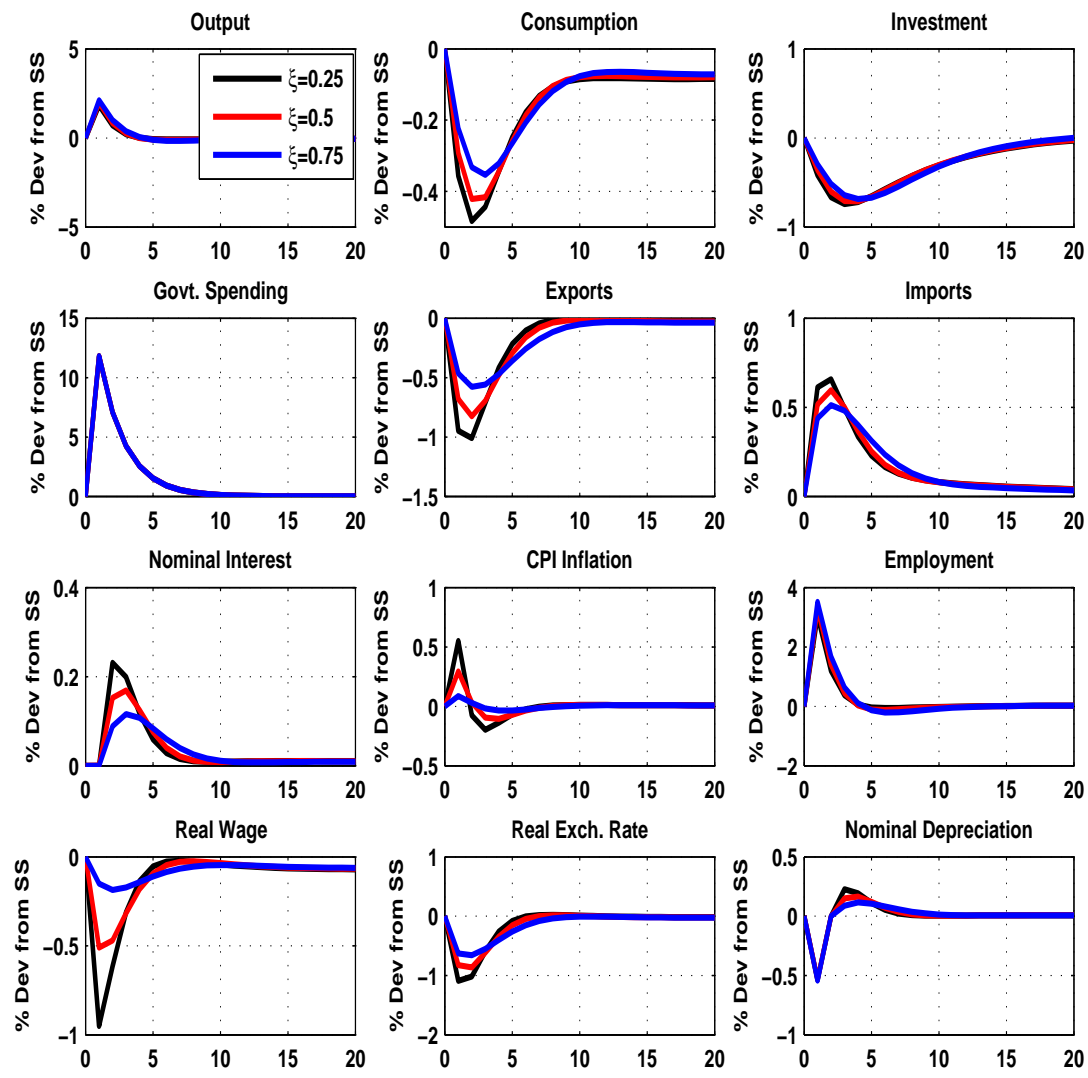

Fig. 2: Impact of price stickiness on fiscal transmission

We run the model under two alternate calibrations that assume $\xi_{d}=\xi_{m, c}=$ $\xi_{m, i}=0.50$ and $\xi_{d}=\xi_{m, c}=\xi_{m, i}=0.75$. As shown in table 1; in line with expectations, value of multipliers rises owing to rise in price stickiness for all horizons. However, given the substantial rise in level of price stickiness (from 0.25 to 0.75 ), corresponding rise in value of multipliers is quite limited. The reason behind the limited rise in multiplier despite substantial rise in price stickiness; as explained by figure 2 , is that variation in output response is quite limited.

Next, we assess how temporary vs. highly persistent (close to permanent) shocks in fiscal spending affect the value of fiscal multipliers. Our baseline calibration for $\rho_{\hat{g}}$ is 0.60 ; which indicates moderate level of inertia. On the other hand, two alternate calibrations include a purely transitory shock e.g. $\rho_{\hat{g}}=0$ and a highly persistent fiscal shock e.g. $\rho_{\hat{g}}=0.90$. Table 1 shows that a purely transitory shock leads to substantially higher multiplier effect in comparison to moderate and highly persistent shock. The reason behind high multiplier associated with transitory shock; as explained by figure 3, is that in case of highly 

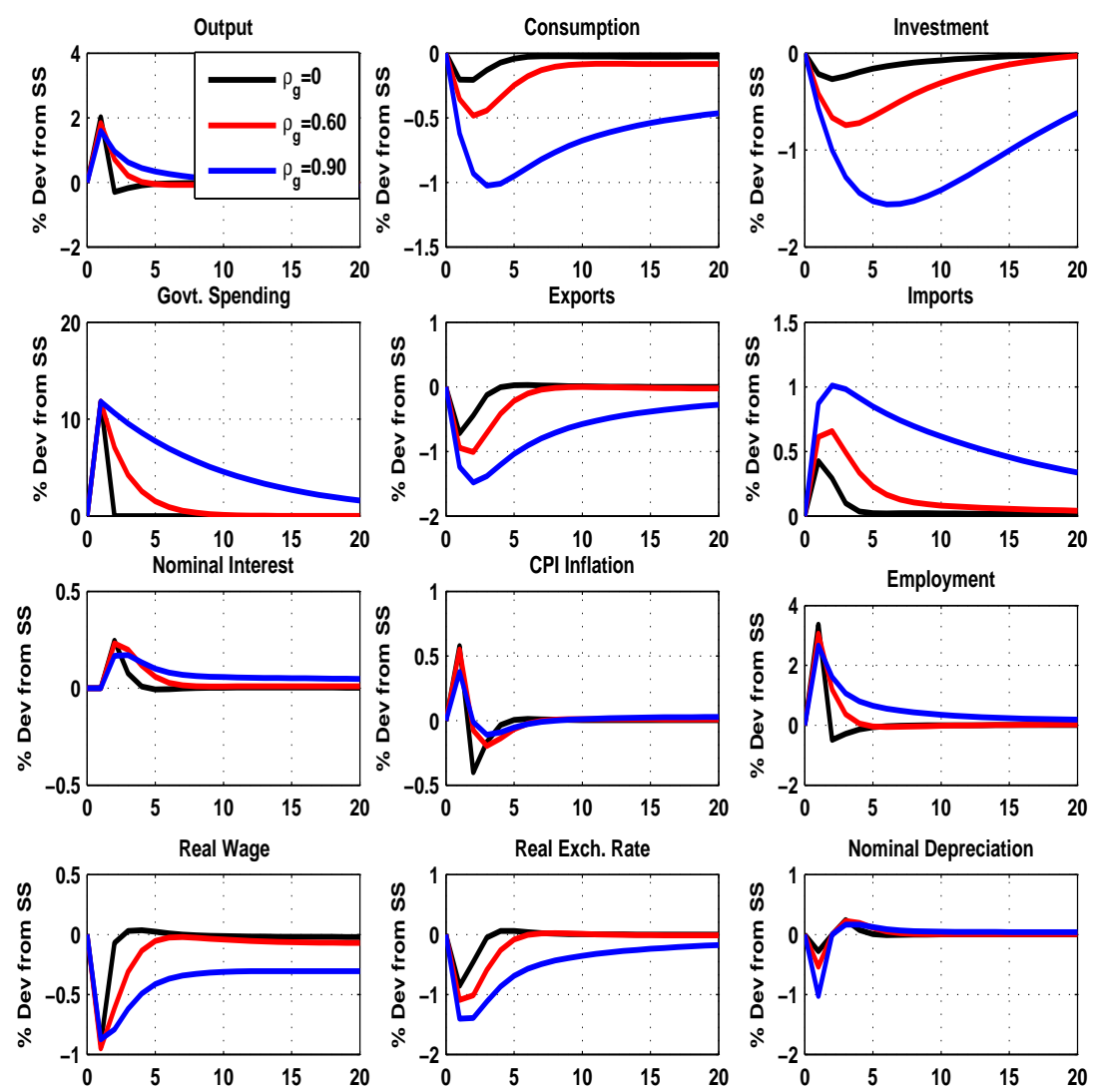

Fig. 3: Impact of shock persistence on fiscal transmission

persistent shock, private consumption, investment and net exports depict strong crowding out effects which are very limited in case of transitory shock.

\section{Conclusion}

We use an estimated open economy DSGE model with real and nominal frictions to analyze fiscal policy transmission mechanism in Pakistan. Our model abstracts productive role of public investment and assumes Ricardian equivalence. Our results show that although fiscal spending positively affects GDP in the short run (multiplier is 0.54 after 1 year) yet, size of output multiplier is very small in the long run (0.18). A fiscal impulse leads to a moderate level of rise in inflation and interest rate accompanied by real appreciation of domestic currency. Private consumption, investment and exports fall owing to negative 
M. Raashid et al.

wealth effect, rise in interest rate and currency appreciation, respectively. Sensitivity analysis shows that the value of the multiplier marginally rises with rise in degree of price stickiness. Transitory shocks have substantially higher multiplier relative to persistent shocks.

Ilzetzki et al (2013) show that value of fiscal multiplier is lower if a country is less developed and exchange rate is flexible. Further, government consumption multiplier is negative if trade is more open and level of public debt is high. However, in case of developing countries, government investment multipliers are positive and significant. Under the light of these insights, our lower estimates of fiscal multiplier are justified as Pakistan has flexible exchange rate, low level of economic development and high level of public debt. While our model has successfully incorporated exchange rate regime and international trade side, elements of public debt and public investment are still missing. In future, the model can be improved by incorporating productive public investment, public debt and, liquidity constrained consumers to relax restrictive assumption of Ricardian equivalence.

\section{References}

Adolfson M, Laseen S, Linde J, Villani M (2005) Bayesian estimation of an open economy DSGE model with incomplete pass-through, working paper, Sveriges Riksbank

Adolfson M, Laseen S, Linde J, Villani M (2007) Bayesian estimation of an open economy DSGE model with incomplete pass-through. Journal of International Economics 72(02):481-511

Ahmad S, Haider A (2019) An evaluation of the forecast performance of DSGE and VAR models: The case of a developing country. Business Review 14(1):28-52

Ahmad S, Pasha F, Rehman M (2016) The role of money in explaining business cycles for a developing economy: The case of Pakistan, state Bank of Pakistan Working Paper Series

Blanchard O, Perotti R (2002) An Empirical Characterization of the Dynamic Effects of Changes in Government Spending and Taxes on Output. The Quarterly Journal of Economics 117(4):1329-1368

Calvo GA (1983) Staggered prices in a utility-maximizing framework. Journal of monetary Economics 12(3):383-398

Choudhary MA, Faheem A, Hanif MN, Naeem S, Pasha F (2016) Price setting and price stickiness: A developing economy perspective. Journal of Macroeconomics 48:44-61

Christiano LJ, Eichenbaum M, Evans CL (2005) Nominal rigidities and the dynamic effects of a shock to monetary policy. Journal of Political Economy 113(1):1-45

Erceg CJ, Henderson DW, Levin AT (2000) Optimal monetary policy with staggered wage and price contracts. Journal of monetary Economics 46(2):281-313

Fontana G (2009) The transmission mechanism of fiscal policy: a critical assessment of current theories and empirical methodologies. Journal of Post Keynesian Economics 31(4):587604, DOI 10.2753/PKE0160-3477310404

Ilzetzki E, Mendoza EG, Vgh CA (2013) How big (small?) are fiscal multipliers? Journal of Monetary Economics 60(2):239 - 254, DOI https://doi.org/10.1016/j.jmoneco.2012.10.011

Javid AY, Arif U (2009) Dynamic effects of changes in government spending in Pakistan's economy. The Pakistan Development Review 48(4):973-988

Khalid M, ul Haq Satti A (2016) Fiscal policy effectiveness for Pakistan: A structural VAR approach. The Pakistan Development Review pp 309-324

Khalid M, Malik WS, Sattar A (2007) The fiscal reaction function and the transmission mechanism for Pakistan. The Pakistan Development Review 46(4):435-447

Munir K, Riaz N (2019) Macroeconomic effects of fiscal policy in Pakistan: a disaggregate analysis. Applied Economics 51(52):5652-5662, DOI 10.1080/00036846.2019.1616074

Ramey VA (2011) Can government purchases stimulate the economy? Journal of Economic Literature 49(3):673-85, DOI 10.1257/jel.49.3.673 
Ramey VA, Shapiro MD (1998) Costly capital reallocation and the effects of government spending. Carnegie-Rochester Conference Series on Public Policy 48:145 - 194, DOI https://doi.org/10.1016/S0167-2231(98)00020-7

Wieland V, Cwik T, Mller GJ, Schmidt S, Wolters M (2012) A new comparative approach to macroeconomic modeling and policy analysis. Journal of Economic Behavior \& Organization 83(3):523 - 541, DOI https://doi.org/10.1016/j.jebo.2012.01.006, the Great Recession: motivation for re-thinking paradigms in macroeconomic modeling

\section{Appendix}

5.1 Linearized version of DSGE model

Following are the final version of linearized equations included in the model.

5.2 Aggregate supply

NKPC for domestic inflation:

$$
\begin{aligned}
\left(\hat{\pi}_{t}-\widehat{\bar{\pi}}_{t}^{c}\right)= & \frac{\beta}{1+\kappa_{D} \beta}\left(E_{t} \hat{\pi}_{t+1}-\widehat{\bar{\pi}}_{t}^{c}\right)+\frac{\kappa_{D}}{1+\kappa_{D} \beta}\left(\hat{\pi}_{t-1}-\widehat{\bar{\pi}}_{t}^{c}\right)- \\
& \frac{\kappa_{D} \beta\left(1-\rho_{\pi}\right)}{1+\kappa_{D} \beta} \widehat{\bar{\pi}}_{t}^{c}+\frac{\left(1-\xi_{d}\right)\left(1-\beta \xi_{d}\right)}{\xi_{d}\left(1+\kappa_{D} \beta\right)} \widehat{m c}_{t}
\end{aligned}
$$

Domestic marginal costs:

$$
\widehat{m c}_{t}=\alpha\left(\hat{\mu}_{z, t}+\hat{H}_{t}-\hat{k}_{t}\right)+\widehat{\bar{w}}_{t}+\hat{R}_{t}^{f}-\hat{\epsilon}_{t}
$$

Capital-labour ratio:

$$
\hat{k}_{t}-\hat{H}_{t}=\hat{\mu}_{z, t}+\hat{R}_{t}^{f}-\hat{r}_{t}^{k}+\widehat{\bar{w}}_{t}
$$

NKPC for imported consumption goods:

$$
\begin{aligned}
\left(\hat{\pi}_{t}^{m, c}-\widehat{\bar{\pi}}_{t}^{c}\right)= & \frac{\beta}{1+\kappa_{m, c} \beta}\left(E_{t} \hat{\pi}_{t+1}^{m, c}-\rho_{\pi} \widehat{\bar{\pi}}_{t}^{c}\right)+\frac{\kappa_{m, c}}{1+\kappa_{m, c} \beta}\left(\hat{\pi}_{t-1}^{m, c}-\widehat{\bar{\pi}}_{t}^{c}\right)- \\
& \frac{\kappa_{m, c} \beta\left(1-\rho_{\pi}\right)}{1+\kappa_{m, c} \beta} \widehat{\bar{\pi}}_{t}^{c}+\frac{\left(1-\xi_{m, c}\right)\left(1-\beta \xi_{m, c}\right)}{\xi_{m, c}\left(1+\kappa_{m, c} \beta\right)} \widehat{m c}_{t}^{m, c}
\end{aligned}
$$

Imported consumption marginal costs:

$$
\widehat{m c}_{t}^{m, c}=\hat{p}_{t}^{*}+\hat{s}_{t}-\hat{p}_{t}^{m, c}
$$

NKPC for imported investment goods:

$$
\begin{aligned}
\left(\hat{\pi}_{t}^{m, i}-\widehat{\bar{\pi}}_{t}^{c}\right)= & \frac{\beta}{1+\kappa_{m, i} \beta}\left(E_{t} \hat{\pi}_{t+1}^{m, i}-\rho_{\pi} \widehat{\bar{\pi}}_{t}^{i}\right)+\frac{\kappa_{m, i}}{1+\kappa_{m, i} \beta}\left(\hat{\pi}_{t-1}^{m, i}-\widehat{\bar{\pi}}_{t}^{c}\right)- \\
& \frac{\kappa_{m, i} \beta\left(1-\rho_{\pi}\right)}{1+\kappa_{m, i} \beta} \widehat{\bar{\pi}}_{t}^{c}+\frac{\left(1-\xi_{m, i}\right)\left(1-\beta \xi_{m, i}\right)}{\xi_{m, i}\left(1+\kappa_{m, i} \beta\right)}\left(\widehat{m c}_{t}^{m, i}+\hat{\lambda}_{t}^{m, i}\right)
\end{aligned}
$$

Business Review: (2020) 15(1):50-66 
M. Raashid et al.

Imported investment marginal costs:

$$
\widehat{m c}_{t}^{m, i}=\hat{p}_{t}^{*}+\hat{s}_{t}-\hat{p}_{t}^{m, i}
$$

NKPC for export goods:

$$
\begin{aligned}
\left(\hat{\pi}_{t}^{x}-\widehat{\bar{\pi}}_{t}^{c}\right)= & \frac{\beta}{1+\kappa_{x} \beta}\left(E_{t} \hat{\pi}_{t+1}^{x}-\rho_{\pi} \widehat{\bar{\pi}}_{t}^{c}\right)+\frac{\kappa_{x}}{1+\kappa_{x} \beta}\left(\hat{\pi}_{t-1}^{x}-\widehat{\bar{\pi}}_{t}^{c}\right)- \\
& \frac{\kappa_{x} \beta\left(1-\rho_{\pi}\right)}{1+\kappa_{x} \beta} \widehat{\bar{\pi}}_{t}^{c}+\frac{\left(1-\xi_{x}\right)\left(1-\beta \xi_{x}\right)}{\xi_{x}\left(1+\kappa_{x} \beta\right)} \widehat{m c}_{t}^{x}
\end{aligned}
$$

Marginal costs for export goods:

$$
\widehat{m c}_{t}^{x}=\hat{p}_{t}-\hat{s}_{t}-\hat{p}_{t}^{x}
$$

Wage inflation:

$$
\begin{gathered}
\hat{R}_{t}^{f}=\frac{\nu R}{\nu R+1-\nu} \hat{R}_{t-1} \\
E_{t}\left[\begin{array}{c}
\eta_{0} \widehat{\bar{w}}_{t-1}+\eta_{1} \widehat{\bar{w}}_{t}+\eta_{2} \widehat{\bar{w}}_{t+1}+\eta_{3}\left(\hat{\pi}_{t}^{d}-\widehat{\bar{\pi}}_{t}^{c}\right)+\eta_{4}\left(\hat{\pi}_{t+1}^{d}-\rho_{\widehat{\bar{\pi}}^{c}} \widehat{\bar{\pi}}_{t}^{c}\right)+ \\
\eta_{5}\left(\hat{\pi}_{t-1}^{d}-\widehat{\bar{\pi}}_{t}^{c}\right)+\eta_{6}\left(\hat{\pi}_{t}^{d}-\rho_{\widehat{\bar{\pi}}^{c}} \widehat{\bar{\pi}}_{t}^{c}\right)+\eta_{7} \hat{\psi}_{z, t}^{\tau}+\eta_{8} \hat{H}_{t}+\eta_{9} \hat{\tau}_{t}^{y}+\eta_{10} \hat{\tau}_{t}^{w}+\eta_{11} \zeta_{t}^{h}
\end{array}\right]=0
\end{gathered}
$$

\subsection{Aggregate demand}

Consumption Euler equation:

$$
E_{t}\left[\begin{array}{c}
-\beta b \mu_{z} \hat{c}_{t+1}+\left(\mu_{z}^{2}+\beta b^{2}\right) \hat{c}_{t}-b \mu_{z} \hat{c}_{t-1}+b \mu_{z}\left(\hat{\mu}_{z, t}-\beta \hat{\mu}_{z, t+1}\right)+ \\
\left(\mu_{z}-\beta b\right)\left(\mu_{z}-b\right) \hat{\psi}_{z, t+1}+\frac{\tau^{c}}{1+\tau^{c}}\left(\mu_{z}-\beta b\right)\left(\mu_{z}-b\right) \hat{\tau}_{t}^{c}+ \\
\left(\mu_{z}-\beta b\right)\left(\mu_{z}-b\right) \hat{\gamma}_{t}^{c, d}-\left(\mu_{z}-b\right)\left(\mu_{z} \hat{\varsigma}_{t}^{c}-\beta b \hat{\varsigma}_{t+1}^{c}\right)
\end{array}\right]=0
$$

Derivative w.r.t. money:

$$
E_{t}\left[-\mu \hat{\psi}_{z, t}+\mu \hat{\psi}_{z, t+1}-\mu \hat{\mu}_{z, t+1}+\left(\mu-\beta \tau^{k}\right) \hat{R}_{t}-\mu \hat{\pi}_{t+1}+\frac{\tau^{k}}{1-\tau^{k}}(\beta-\mu) \hat{\tau}_{t+1}^{k}\right]=0
$$

Money growth:

$$
\mu_{t}=\widehat{\bar{m}}_{t+1}+\hat{\mu}_{z, t}+\hat{\pi}_{t}
$$

Derivative w.r.t. capital:

$$
E_{t}\left[\begin{array}{c}
\hat{\psi}_{z, t}+\hat{\mu}_{z, t+1}-\hat{\psi}_{z, t+1}-\frac{\beta(1-\delta)}{\mu_{z}} \hat{P}_{k^{\prime}, t+1}+\hat{P}_{k^{\prime}, t} \\
-\frac{\mu_{z}-\beta(1-\delta)}{\mu_{z}} \hat{r}_{t+1}^{k}+\frac{\tau^{k}}{1-\tau^{k}} \frac{\mu_{z}-\beta(1-\delta)}{\mu_{z}} \hat{\tau}_{t+1}^{k}
\end{array}\right]=0
$$

Derivative w.r.t. investment:

$$
E_{t}\left[P_{k^{\prime}, t}+\hat{\Upsilon}_{t}-\hat{\gamma}_{t}^{i, d}-\mu_{z}^{2} \tilde{S}^{\prime \prime}\left[\left(\hat{\imath}_{t}-\hat{\imath}_{t-1}\right)-\beta\left(\hat{\imath}_{t+1}-\hat{\imath}_{t}\right)+\hat{\mu}_{z, t}-\beta \hat{\mu}_{z, t+1}\right]\right]=0
$$

Derivative w.r.t. rate of capital utilization:

$$
\hat{u}_{t}=\frac{1}{\sigma} \hat{r}_{t}^{k}-\frac{1}{\sigma_{a}} \frac{\tau^{k}}{1-\tau^{k}} \hat{\tau}_{t}^{k}
$$

62 
Definition of variable capacity utilization:

$$
\hat{u}_{t}=\hat{k}_{t}-\widehat{\bar{k}}_{t}
$$

UIP condition:

$$
E_{t} \Delta \hat{S}_{t+1}-\left(\hat{R}_{t}-\hat{R}_{t}^{*}\right)-\tilde{\phi}_{a} \hat{a}_{t}+\widehat{\tilde{\phi}}_{t}=0
$$

Derivative w.r.t. cash holding:

$$
\hat{q}_{t}=\frac{1}{\sigma_{q}}\left[\hat{\varsigma}_{t}^{q}+\frac{\tau^{k}}{1-\tau^{k}} \hat{\tau}_{t}^{k}-\hat{\psi}_{z, t}-\frac{R}{1-R} \hat{R}_{t}\right]
$$

\subsection{Government and Central Bank}

Taylor-type interest rate rule

$$
\hat{R}_{t}=\rho_{R} \hat{R}_{t-1}+\left(1-\rho_{R}\right)\left(\hat{\bar{\pi}}_{t}^{c}+\rho_{\pi}\left(\hat{\pi}_{t}^{c}-\widehat{\bar{\pi}}_{t}^{c}\right)+\rho_{y} \hat{y}_{t-1}\right)+\varepsilon_{R, t}
$$

CPI inflation:

$$
\widehat{\pi}_{t}^{c}=\left[\left(1-\omega_{c}\right)\left(\gamma^{d, c}\right)^{\left(1-\eta_{c}\right)}\right] \hat{\pi}_{t}^{d}+\left[\omega_{c}\left(\gamma^{m c, c}\right)^{\left(1-\eta_{c}\right)}\right] \hat{\pi}_{t}^{m, c}
$$

Production function:

$$
\hat{y}_{t}=\lambda_{d}\left[\hat{\epsilon}_{t}+\alpha \hat{K}_{t}+(1-\alpha) \hat{H}_{t}\right]
$$

Exchange rate gap:

$$
\begin{gathered}
\hat{x}_{t}=-\omega_{c}\left(\gamma^{m c, c}\right)^{-\left(1-\eta_{c}\right)} \gamma^{m c, d}-\hat{\gamma}_{t}^{x, *}-\widehat{m c}_{t}^{x} \\
\hat{x}_{t}=\hat{S}_{t}+\hat{P}_{t}^{*}-\hat{P}_{t}^{c}
\end{gathered}
$$

Aggregate resource constraint:

$$
\begin{aligned}
& \left(1-\omega_{c}\right)\left(\gamma^{c, d}\right)^{\eta_{c}} \frac{c}{y}\left(c_{t}+\eta_{c} \hat{\gamma}_{t}^{c, d}\right)+\left(1-\omega_{i}\right)\left(\gamma^{i, d}\right)^{\eta_{i}} \frac{i}{y}\left(i_{t}+\eta_{i} \hat{\gamma}_{t}^{i, d}\right)+\frac{g}{y} \hat{g}_{t}+ \\
& \frac{y^{*}}{y}\left(y_{t}^{*}-\eta_{f} \hat{\gamma}_{t}^{x, *}+\widehat{\widetilde{z}}_{t}^{*}\right)=\lambda_{d}\left(\hat{\epsilon}_{t}+\alpha\left(\hat{k}_{t-} \hat{\mu}_{z, t}\right)+(1-\alpha) \hat{H}_{t}\right)-\left(1-\tau^{k}\right) r^{k} \frac{\bar{k}}{y} \frac{1}{\mu_{z}}\left(\hat{k}_{t}-\widehat{\bar{k}}_{t}\right)
\end{aligned}
$$

Capital accumulation constraint:

$$
\widehat{\bar{k}}_{t+1}=(1-\delta) \frac{1}{\mu_{z}}\left(\widehat{\bar{k}}_{t}-\hat{\mu}_{z, t}\right)+\left(1-(1-\delta) \frac{1}{\mu_{z}}\right)\left(\hat{\imath}_{t}+\hat{\Upsilon}_{t}\right)
$$

Net foreign assets:

$$
\begin{aligned}
\hat{a}_{t}= & -y^{*} \widehat{m c}_{t}^{x}-\eta_{f} y^{*} \hat{\gamma}_{t}^{x, *}+y^{*} \hat{y}_{t}^{*}+y^{*} \widehat{\widetilde{z}}_{t}^{*}+\left(c^{m}+i^{m}\right) \hat{\gamma}_{t}^{f}- \\
& c^{m}\left(-\eta_{c}\left(1-\omega_{c}\right)\left(\gamma^{c, d}\right)^{-\left(1-\eta_{c}\right)} \hat{\gamma}_{t}^{m c, d}+\hat{c}_{t}\right)+ \\
& i^{m}\left(-\eta_{i}\left(1-\omega_{i}\right)\left(\gamma^{i, d}\right)^{-\left(1-\eta_{i}\right)} \hat{\gamma}_{t}^{m i, d}+\hat{\imath}_{t}\right)+\frac{R}{\pi \mu_{z}} \hat{a}_{t-1}
\end{aligned}
$$

Business Review: (2020) 15(1):50-66 
M. Raashid et al.

Loan market clearing condition:

$$
\nu \bar{w}_{t} H\left(\hat{w}_{t}+\hat{H}_{t}\right)=\frac{\mu \bar{m}}{\mu_{z} \pi}\left(\hat{\mu}_{t}+\widehat{\bar{m}}_{t}-\hat{\pi}_{t}-\hat{\mu}_{z, t}\right)
$$

Relative prices:

$$
\begin{gathered}
\hat{\gamma}_{t}^{m c, d}=\hat{\gamma}_{t-1}^{m c, d}+\pi_{t}^{m, c}-\pi_{t}^{d} \\
\hat{\gamma}_{t}^{m i, d}=\hat{\gamma}_{t-1}^{m i, d}+\pi_{t}^{m, i}-\pi_{t}^{d} \\
\hat{\gamma}_{t}^{x, *}=\hat{\gamma}_{t-1}^{x, *}+\pi_{t}^{x}-\pi_{t}^{*} \\
\widehat{m c}_{t}^{x}=\widehat{m c}_{t-1}^{x}+\pi_{t}-\pi_{t}^{x}-\Delta \hat{S}_{t} \\
\hat{\gamma}_{t}^{f}=\widehat{m c}_{t}^{x}+\hat{\gamma}_{t}^{x, *} \\
\hat{\gamma}_{t}^{c, d}=\omega_{c} \gamma^{m c, c\left(1-\eta_{c}\right)} \hat{\gamma}_{t}^{m c, d} \\
\hat{\gamma}_{t}^{i, d}=\omega_{i} \gamma^{m i, i\left(1-\eta_{i}\right)} \hat{\gamma}_{t}^{m i, d}
\end{gathered}
$$

5.5 Exogenous shocks

Transitory technology shock:

$$
\hat{\epsilon}_{t}=\rho_{\epsilon} \hat{\epsilon}_{t-1}+\varepsilon_{t}
$$

Consumption preference shock:

$$
\hat{\varsigma}_{t}^{c}=\rho_{\varsigma^{c}} \hat{\zeta}_{t-1}^{c}+\varepsilon_{\varsigma^{c}, t}
$$

Labour supply shock:

$$
\hat{\varsigma}_{t}^{h}=\rho_{\varsigma^{h}} \hat{\varsigma}_{t-1}^{h}+\varepsilon_{\varsigma^{h}, t}
$$

FX risk-premium shock:

$$
\widehat{\tilde{\phi}}_{t}=\rho_{\widetilde{\tilde{\phi}}} \widehat{\tilde{\phi}}_{t-1}+\varepsilon \varepsilon_{\tilde{\phi}, t}
$$

Fiscal spending shock:

$$
\hat{g}_{t}=\rho_{\hat{g}} \hat{g}_{t-1}+\epsilon_{t}^{\hat{g}}
$$

Foreign output:

$$
y_{t}^{*}=\rho_{y^{*}} y_{t-1}^{*}+\varepsilon_{y^{*}, t}
$$

Foreign inflation:

$$
\pi_{t}^{*}=\rho_{\pi^{*}} \pi_{t-1}^{*}+\varepsilon_{\pi^{*}, t}
$$

Foreign interest rate:

$$
R_{t}^{*}=\rho_{R^{*}} R_{t-1}^{*}+\varepsilon_{R^{*}, t}
$$


https://ir.iba.edu.pk/businessreview/vol15/iss1/10

DOI: https://doi.org/10.54784/1990-6587.1009

Fiscal policy transmission...

5.6 Calibration of parameters

Table 2: Calibration of shock parameters

\begin{tabular}{c|c|l|c}
\hline Sr. No. & Symbol & Parameter & Value \\
\hline 1 & $\rho_{\varepsilon}$ & Persistence of transitory tech. shock & 0.885 \\
2 & $\rho_{\hat{g}}$ & Persistence of fiscal spending shock & 0.60 \\
3 & $\rho_{\tilde{\phi}}$ & Persistence of FX risk prem. shock & 0.969 \\
4 & $\rho_{\phi^{*}}$ & Persistence of foreign inflation shock & 0.547 \\
5 & $\rho_{y^{*}}$ & Persistence of foreign demand shock & 0.961 \\
6 & $\rho_{R^{*}}$ & Persistence of foreign interest rate shock & 0.948 \\
7 & $\rho_{\zeta_{c}}$ & Persistence of consumer preference shock & 0.80 \\
8 & $\rho_{\zeta_{h}}$ & Persistence of labor supply shock & 0.80 \\
9 & $\sigma_{\varepsilon}$ & SD of transitory tech. shock & 0.014 \\
10 & $\sigma_{g}$ & SD of fiscal spending shock & 0.118 \\
11 & $\sigma_{R}$ & SD of monetary policy shock & 0.005 \\
12 & $\sigma_{\tilde{\phi}}$ & SD of FX risk prem. shock & 0.005 \\
13 & $\sigma_{\pi^{*}}$ & SD of foreign inflation shock & 0.005 \\
14 & $\sigma_{y^{*}}$ & SD of foreign inflation shock & 0.007 \\
15 & $\sigma_{R^{*}}$ & SD of foreign interest rate shock & 0.002 \\
16 & $\sigma_{\zeta_{c}}$ & SD of consumer preference shock & 0.05 \\
17 & $\sigma_{\zeta_{h}}$ & SD of labor supply shock & 0.01 \\
\hline
\end{tabular}

Business Review: (2020) 15(1):50-66 
M. Raashid et al.

Table 3: Calibration of structural parameters

\begin{tabular}{|c|c|c|c|}
\hline Sr. No. & Symbol & Parameter & Value \\
\hline 1 & $\beta$ & Discount factor & 0.99 \\
\hline 2 & $\eta_{c}$ & Elasticity of subs. bw. domestic and foreign consumption goods & 0.8 \\
\hline 3 & $\eta_{i}$ & Elasticity of subs. bw. domestic and foreign investment goods & 0.8 \\
\hline 4 & $\eta_{f}$ & Elasticity of subs. bw. different countries goods & 2 \\
\hline 5 & $A_{q}$ & Weight of cash holding in utility function & 0.88 \\
\hline 6 & $A_{L}$ & Weight of labour supply in utility function & 5.2 \\
\hline 7 & $\omega_{i}$ & Share of foreign goods in total investment & 0.3 \\
\hline 8 & $\omega_{c}$ & Share of foreign goods in total consumption & 0.3 \\
\hline 9 & $\lambda^{w}$ & Steady state mark-up for labour supply & 1.05 \\
\hline 10 & $\lambda^{d}$ & Mark-up for domestic goods & 1.2 \\
\hline 11 & $\lambda^{m, c}$ & Mark-up for imported consumer goods & 1.2 \\
\hline 12 & $\lambda^{m, i}$ & Mark-up for imported investment goods & 1.2 \\
\hline 13 & $\xi_{w}$ & Calvo price stickiness index for wages & 0.7 \\
\hline 14 & $\xi_{d}$ & Calvo price stickiness index for domestic goods & 0.25 \\
\hline 15 & $\xi_{m, c}$ & Calvo coefficient for imported consumption goods & 0.25 \\
\hline 16 & $\xi_{m, i}$ & Calvo coefficient for imported investment goods & 0.25 \\
\hline 17 & $\xi_{x}$ & Calvo coefficient for exported goods & 0.7 \\
\hline 18 & $\kappa_{w}$ & Wage indexation coefficient & 0.5 \\
\hline 19 & $\kappa_{d}$ & Price indexation for domestic goods & 0.3 \\
\hline 20 & $\kappa_{m, c}$ & Price indexation for imported consumer goods & 0.3 \\
\hline 21 & $\kappa_{m, i}$ & Price indexation for investment goods & 0.3 \\
\hline 22 & $\bar{g}$ & Steady state fiscal spending to GDP ratio & 0.2 \\
\hline 23 & $\mu$ & Steady state money growth rate & 1.025 \\
\hline 24 & $\tau_{y}$ & Steady state labor income tax & 0.1 \\
\hline 25 & $\tau_{c}$ & Steady state value added tax & 0.17 \\
\hline 26 & $\tau_{w}$ & Steady state payroll tax & 0.05 \\
\hline 27 & $\tau_{k}$ & Steady state capital income tax & 0.2 \\
\hline 28 & $\alpha$ & Capital share in production & 0.5 \\
\hline 29 & $\delta$ & Depreciation rate & 0.0164 \\
\hline 30 & $\mu_{z}$ & Steady state tech. growth rate & 1.006 \\
\hline 31 & $\bar{\pi}$ & Steady state inflation & 1.019 \\
\hline 32 & $\nu$ & Share of firms need working finance & 0.2 \\
\hline 33 & $\tilde{S}$ & Investment adjustment costs curvature & 12.67 \\
\hline 34 & $\sigma_{a}$ & Capital utilization costs coefficient & 10.6 \\
\hline 35 & $\sigma_{q}$ & Inverse elasticity of cash holding demand & 10.62 \\
\hline 36 & $b$ & Habit formation in consumption & 0.58 \\
\hline 37 & $\sigma_{L}$ & Inverse elasticity of labour supply & 0.81 \\
\hline 38 & $\phi_{a}$ & Sensitivity of exchange rate changes to FX risk premium & 0.006 \\
\hline 39 & $\rho_{R}$ & Interest rate smoothing in interest rate rule & 0.88 \\
\hline 40 & $\rho_{\pi}$ & Monetary policy response to inflation & 2.7 \\
\hline 41 & $\rho_{y}$ & Monetary policy response to output gap & 0.24 \\
\hline
\end{tabular}

